\title{
The Effect of Mycotoxins in Naturally Contaminated Diet on the Pathogenicity of Escherichia coli in Broiler Chickens
}

\author{
Mohamed Mohamed Batikh ${ }^{1}$, Anwaar Mettwally El-nabarawy ${ }^{2}$, Mohamed Abdel-salam Shakal ${ }^{2}$, Abdel-Haleem \\ Mohamed Hegazy ${ }^{1}$, and Eman Anter Morsy ${ }^{2 *}$ \\ ${ }^{1}$ Poultry diseases department, animal health research institute-Kafr El-sheikh provisional lab, agriculture research center, Egypt \\ ${ }^{2}$ Poultry diseases department- Faculty of veterinary medicine-Cairo University, Egypt Giza 12211, Egypt \\ *Corresponding author: emananter@cu.edu.eg; (DORCiD: 0000-0002-1906-5416
}

\begin{abstract}
Contamination of feedstuffs with mycotoxins is considered a huge issue plaguing the poultry sector of Egypt. Therefore, the current study was conducted to examine the effect of the neglected natural mycotoxin contamination of ration on the clinicopathological picture of Escherichia coli infection in broiler chickens. A total of 240 one-dayold chicks were divided into 5 groups. The first 3 groups $(1,2$, and 3 ) were further equally subdivided into 2 subgroups (A and B). Those in group A were fed on commercial ration treated with antimycotoxin while group B was fed on ration contaminated with mycotoxins. Groups 1, 2, and 3 were inoculated at one-day-old with E. coli $\mathrm{O}_{78}$, $\mathrm{O}_{128}$, and $\mathrm{O}_{157}$, respectively while group 4 was kept as a negative control and fed on a ration treated with antimycotoxin. Finally, group 5 was kept as positive controls and fed on a mycotoxin contaminated ration and inoculated with physiological saline. All groups contained 30 chicks. Results showed that the challenged groups fed on a ration containing mycotoxin had high mortality $(23.3 \%)$ and also a high feed conversion ratio. Moreover severe clinical symptoms, postmortem lesions, histopathological pictures, and a high rate of bacterial re-isolation were recorded. The pathological lesions were congestion of the liver, spleen, and kidneys in addition to severe pericarditis, perihepatitis, air sacullitis, ascites, and unabsorbed yolk sac. The histopathological changes included degeneration, necrosis, and liver inflammation with lymphoid depletion in the spleen and enteritis associated with sloughing of the mucosal epithelium. The obtained results were less severe in the challenged groups fed on a ration treated with antimycotoxin indicating combined action of both Escherichia coli and mycotoxins. In conclusion, the obtained results revealed that the mycotoxins even at low concentrations can augment the pathogenisity of Echerichia coli in broiler chickens.
\end{abstract}

Keywords: Broiler chicken, Clinicopathological finding, Escherichia coli, Histopathology, Mycotoxin, Organ colonization

\section{INTRODUCTION}

Mycotoxins are biologically active, toxic metabolites produced by toxigenic fungi that invade crops in the farm fields and may grow on feed during storage in case of desired temperature and humidity conditions (Shamsudeen et al., 2013). There are about 200 species of fungi that produce mycotoxins, the majority of which form mycotoxins in three genera of Aspergillus, Penicillium, and Fusarium. Even though these fungi produce over 500 mycotoxins, only a subset of these mycotoxins (mainly Aflatoxin, Ochratoxin, Zeralenone, Fuminisin) are pathogenic (Filazi et al., 2017). Natural mycotoxin contamination of feedstuffs is regarded as a major issue affecting the poultry industry of Egypt (El Nabarawy et al., 2020).

Different mycotoxin types had a synergistic highly toxic and fatal impact even at low concentrations (Boermans and Leung, 2007; Streit et al., 2012). The most significant mycotoxins affecting poultry through naturally contaminated feeds are aflatoxin (AF), ochratoxin A (OTA), zearalenone, T-2 toxin, vomitoxin, and fumonisin, which have serious toxic effects and possibly synergistic properties (Njobeh et al., 2012).

Naturally contaminated broiler diets with aflatoxin, ochratoxin (OTA), and zearalenone at permissible levels lead to a significantly decreased body weight (El Nabarawy et al., 2020). Mycotoxin-related clinical signs and pathological lesions are closely related to poultry species, mycotoxin type, dose consumed, and duration of exposure. Chickens are exposed to multiple mycotoxins and subjected to a broader range of stressors in the field. Accordingly, even with apparently low levels of mycotoxins in the feed, chickens may exhibit signs and lesions of mycotoxicosis (Rodrigues and Naehrer, 2012). 
Colibacillosis, on the other hand, is one of the most common infectious diseases in farmed poultry and one of the leading causes of morbidity and mortality in young chickens (Stordeur and Manil, 2002). The link between Escherichia coli $(E$. coli) strains and disease conditions in avian species was discovered over a century ago (Sojka and Carnaghan, 1961). Some mycotoxins interfere with host defenses against E. coli, resulting in bacterial clearance failure and promoting mucosal colonization, invasion, and inflammatory responses. Consequently, mycotoxins can make hosts more susceptible (Park et al., 2015).

Ochratoxin $(80 \mathrm{mg} / \mathrm{kg}$, in vivo) exacerbates E. coli infection-mediated diseases in broiler chickens, such as perihepatitis and pericarditis, and increases the thickness of the fibrin layer that covers the heart and liver after $E$. coli infection (Kumar et al., 2004). Thus, the goal of this study was to investigate the effect of natural contamination of mycotoxins (Aflatoxin and Ochratoxin) on the clinicopathological picture of day-old CUBB broiler chicks infected with different pathogenic E. coli serotypes.

\section{MATERIAL AND METHODS}

\section{Ethical approval}

Chicken handling procedures during the experiment were performed and approved by the institutional animal care and use committee of the Faculty of Veterinary Medicine, Cairo University, Egypt (VetCU02122019108).

\section{Experimental chickens}

One-day-old CUBB chicks $(n=240)$ were purchased from AL-WATANIA company (Egypt). All used chicks were from the same breeding stock. Feed and water were delivered to the broiler chickens ad libitum. All the chickens in the experiment were floor reared in separate pens at a density of 10 broiler chicks $/ \mathrm{m} 2$ on a concrete floor with fresh wood shavings as bedding and housed in environmentally controlled rooms. At 7 and 10 days of age, chickens in all groups were vaccinated against NDV $+\mathrm{IBV}$ with Hitchner $\mathrm{B} 1+\mathrm{H}_{120}$ vaccine and avian influenza inactivated $\mathrm{H}_{5} \mathrm{~N}_{2}$ vaccine via intraocular and subcutaneous routes, respectively. The La Sota vaccination and the IBDV vaccine were administered intra-ocularly on days 14 and 18 of life, respectively. The broiler chicks were maintained on broiler mash from day 1 to day 28.

\section{Chicken diet}

A balanced commercial ration for broiler chickens in the form of a mash diet was purchased from a commercial factory (Alshimaa factory in Kafr El-Shiekh Governorate, Egypt) without any additives. Mycotoxins analysis in the ration was performed for Aflatoxin, Ochratoxin, and Zeralenone using high-performance liquid chromatography (HPLC) (El Nabarawy et al., 2020)

\section{Antimycotoxin medication}

Antimycotoxin medication (containing cell wall extract derived from hydrolyzed yeast and hydrated sodium calcium aluminosilicate with a dose of 250gram/tone) was used in the groups fed ration without antimycotoxins (the B groups in addition to the positive control group) during the 4 weeks of the experiment.

\section{Experimental design}

The study was extended from one day of age up to 28 days. On day 1, chicks were randomly assigned into five groups (1-5). The first three groups contained 60 chicks each, which were further divided into two subgroups (A and B) each one with 30 chicks while groups 4 and 5 contained 30 chicks each and were kept as a negative (-ve) and a positive (+ve) controls, respectively. The A groups (from the first 3 groups) fed on antimycotoxin-treated ration, while the B groups (from the first 3 groups) fed on a diet containing mycotoxin within permissible limits of the Egyptian regulations (10 ppb Aflatoxin, and $20 \mathrm{ppb}$ Ochratoxin) with their amounts measured using HPLC (aflatoxin was 3 PPB and ochratoxin was 6 PPB while Zearalenone mycotoxin was undetected) according to El Nabarawy et al. (2020). Chicks in group 4 (-ve controls) fed on antimycotoxin-treated ration, while those in group 5 (+ve controls) fed on mycotoxins contaminated ration. The first three groups $(1,2,3)$ with their two subgroups (A and B) were inoculated with $E$. coli serotype $\mathrm{O}_{78}, \mathrm{O}_{128}$, and $\mathrm{O}_{157}$, respectively, at a dose of $1.5 \times 10^{8} \mathrm{CFU} /$ chick via oral route using a feeding tube (Ibrahiem et al., 2016), while groups 4 and 5 were inoculated with physiological saline. The broiler chicks were housed in separated units under similar management and biosecurity parameters for four weeks (Table 1).

The clinical signs, mortality rate, post mortem lesions were recorded daily. Chicken performance response was determined after North (1985). All broiler chicks were individually weighed on the first day and weekly for body weight and body weight gain along with the duration of the experiment. Feed consumption was measured on the same days as the weights of the broiler chicks were done. FCR was calculated ( $\mathrm{g}$ feed/g live body weight) following Timmerman et al. (2006). Organ samples were collected weekly for histopathological examination and bacterial re-isolation. 
Table 1. Experimental design of different pathogenic E. coli serotypes in broiler chickens in the presence of low concentrations of afla and ochratoxins mycotoxins

\begin{tabular}{|c|c|c|c|c|c|c|c|c|}
\hline \multirow{3}{*}{ Total no. of chicks/group } & \multicolumn{2}{|c|}{ Group 1} & \multicolumn{2}{|c|}{ Group 2} & \multicolumn{2}{|c|}{ Group 3} & \multirow{3}{*}{$\begin{array}{c}\text { Group 4 } \\
\text { Control negative } \\
30\end{array}$} & \multirow{3}{*}{$\begin{array}{c}\text { Group 5 } \\
\text { Control positive } \\
30\end{array}$} \\
\hline & \multicolumn{6}{|c|}{ Escherichia Coli challenged groups } & & \\
\hline & \multicolumn{2}{|c|}{60} & \multicolumn{2}{|c|}{60} & \multicolumn{2}{|c|}{60} & & \\
\hline Sub-grouping & A & B & A & B & A & B & - & - \\
\hline No. of chicks/ subgroup & 30 & 30 & 30 & 30 & 30 & 30 & 30 & 30 \\
\hline $\begin{array}{l}\text { E. coli serotype } \\
1.5 \times 10^{8} \mathrm{CFU} / \text { Chick }\end{array}$ & $\mathrm{O}_{78}$ & $\mathrm{O}_{78}$ & $\mathrm{O}_{128}$ & $\mathrm{O}_{128}$ & $\mathrm{O}_{157}$ & $\mathrm{O}_{157}$ & - & - \\
\hline Mycotoxin contaminated ration & - & + & - & + & - & + & - & + \\
\hline Mycotoxin treated ration & + & - & + & - & + & - & + & - \\
\hline
\end{tabular}

\section{Histopathological examination}

Specimens from the liver, kidney, and intestine were collected weekly by sacrificing 2 chickens from each group for histopathological investigation. Samples were collected in jars containing $10 \%$ formol saline then tissue specimens were washed, dehydrated, embedded in paraffin, sectioned at 4-5 $\mu \mathrm{m}$ thickness, and then stained with Hematoxylin and Eosin (H\&E) as a routine work for histopathological studies (Bancroft and Stevens, 1990). The lesion was recorded as a cumulative lesion scoring (Hepatic lesions received 9 scores (3 degeneration, 3 necrosis, and 3 inflammation) and lymphoid depletion in the spleen received 3 scores while intestinal lesions in the form of enteritis received 3 scores) based on Hegazy (1991).

\section{Escherichia coli re-isolation}

The organ colonization was conducted using liver, spleen, and heart samples from all groups collected weekly during the experiment. A swab from these organs was immersed in MacConkey broth (Oxoid, UK), which incubated at $37^{\circ} \mathrm{C}$ for 24 hours, then a loopful was streaked onto MacConkey agar (Oxoid, UK) and Eosin methylene blue (EMB) agar (Oxoid, UK) and incubated at $37^{\circ} \mathrm{C}$ for 24 hours and the E. coli suspected colonies were stored on agar slant in the refrigerator at $4^{\circ} \mathrm{C}$ for further investigation (Azza et al., 2018).

\section{Statistical analysis}

The data were statistically analyzed using the general linear model procedure of the Statistical Analysis System software (SAS, 1999). Overall data were analyzed using one-way ANOVA test through Tukey and a significant level was defined as $\mathrm{p} \leq 0.05$ (Snedecor and Cochran, 1980).

\section{RESULTS AND DISCUSSION}

\section{Clinical signs and post-mortem lesions}

Clinical signs appeared at day 3 post E. coli infection in the experimental groups. Dullness, anxiety, wing drooping, anorexia, ruffled feathers, inability to stand, gasping, and white diarrhea that progressed to brownish diarrhea were among the observed clinical signs. Later, sneezing and coughing were recorded. Upon necropsy of died or sacrificed chickens, the postmortem picture indicated congestion of the liver, lung, spleen, and kidneys, severe pericarditis, perihepatitis, airsaculitis, ascites, and unabsorbed yolk sac (Figure 1). The previously mentioned clinical signs and PM lesions were more severe in the B groups that challenged with E. coli and feed on ration contaminated with low concentrations of Afla and Ochratoxin than the A groups that challenged with E. coli and feed on mycotoxin treated diet. This may be due to the effect of mycotoxins on various organs, such as the gastrointestinal tract and liver (Murugesan et al., 2015). Furthermore, the robust clinical signs and pathological pictures in the mycotoxicated challenged groups may be related to the immunosuppressive effect of mycotoxins on the chicken immune system as mentioned by Murugesan et al. (2015). In other words, mycotoxins can affect activated and proliferating cells by decreasing lymphocyte proliferation, impairing macrophage phagocytic function, and suppressing cytokine production, damaging epithelial tissue, increasing intestinal permeability, and thus resulting in a weakened immune system (Park et al., 2015). Accordingly, when a pathogen enters, an appropriate and efficient immune response cannot be mounted which worsens clinical signs and PM lesions. Similarly, Park et al. (2015) mentioned that mycotoxin could suppress the immune response and increase the inflammatory response. Moon et al. (1999) also explained that mycotoxins can intervene the innate immunity of macrophages by suppressing tumor necrosis factor- $\alpha$ (TNF- $\alpha$ ), interleukin (IL)-1, and IL-6, resulting in the disruption of pulmonary and systemic host defenses, and consequently increase susceptibility to bacterial infections. However, on day 21 post-infection, the clinical signs were insignificant in all challenging groups. 


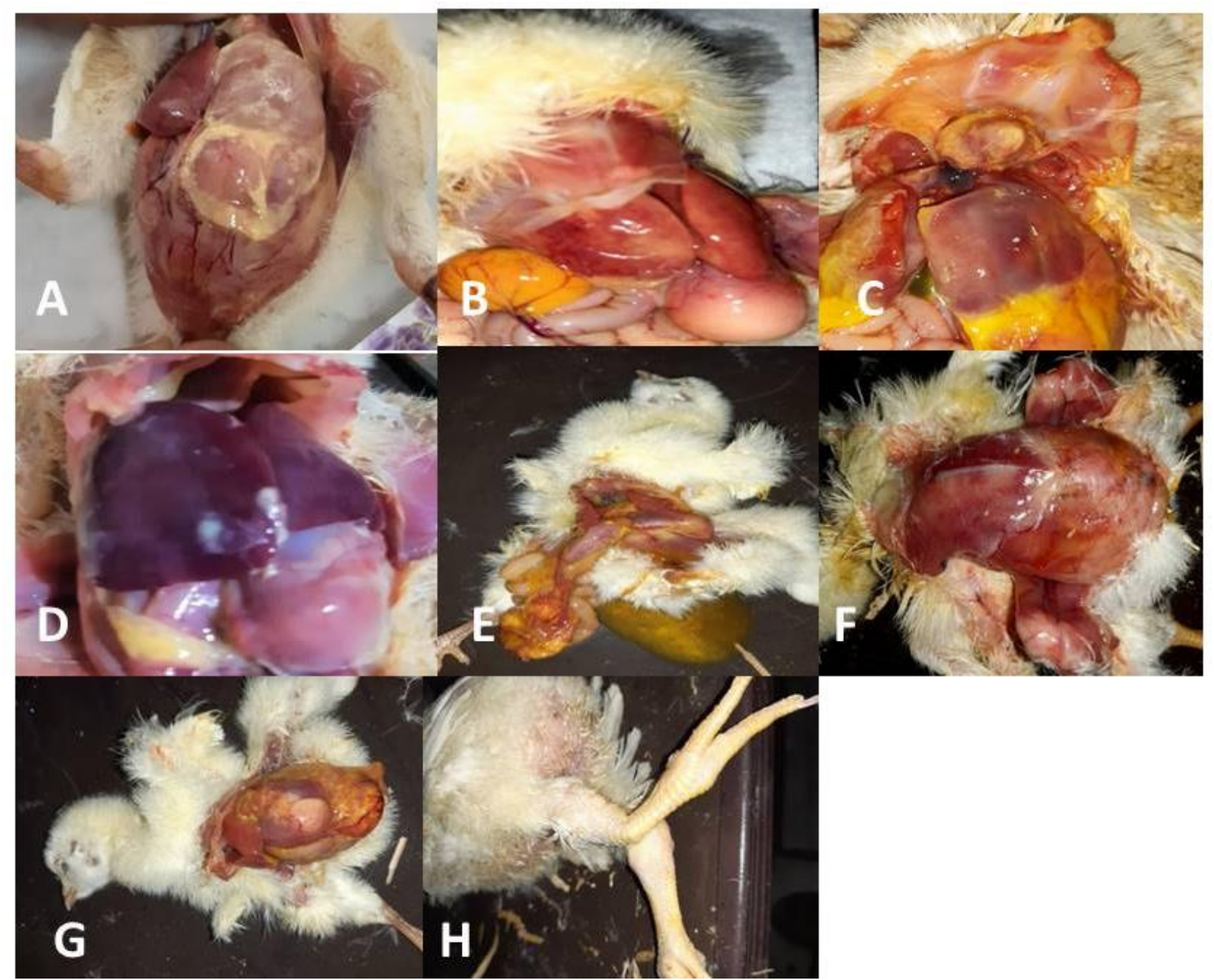

Figure 1. Post mortem lesions observed in the broiler chickens challenged with E. coli O78, E. coli O128, and E. coli O157 during 4 weeks of the experiment. A, B, and C: Unabsorbed yolk sac, congested liver, pericarditis, and perihepatitis in mycotoxicated challenged Escheichia coli $\mathrm{O}_{78}$ group. D and E: Unabsorbed yolk sac and pericarditis in E. coli $\mathrm{O}_{128}$ groups $\mathbf{F}$, G, and H: Ascites and congested carcass unabsorbed yolk sac, and Greenstick fracture bones in E. coli inoculated and mycotoxicated groups

\section{Mortality}

The mortality pattern began at the 5 DPI. The $E$. coli $\mathrm{O}_{78}$ group had the highest mortality rate, followed by the $E$. coli $\mathrm{O}_{157}$ inoculated group, and finally the E. coli $\mathrm{O}_{128}$ infected group. The highest death rate was found in the E. coli $\mathrm{O}_{78}$ group, followed by the E. coli $\mathrm{O}_{157}$ and the lowest in the E. coli $\mathrm{O}_{128}$ group. However, no mortalities were recorded in the controls as mentioned in Table 2. In the present study, the mortality rate of E. coli $\mathrm{O}_{78}(16.7 \%)$ was higher than that reported by Tawab et al. (2015) as $10 \%$ in E. coli $\mathrm{O}_{78}$ groups. Likewise, Shen-Orr et al. (2002) recorded a mortality rate of $8 \%$ induced by E. coli infection in broiler chickens, on the other hand, the mortality rate in the mycotoxin treated group was lower than that reported by Abd El-Ghany and Madian, (2011) who recorded a mortality rate of 38\% (19 out of 50) in broiler chickens infected with E. coli $\mathrm{O}_{78}$. The current study recorded a mortality rate of $8.3 \%$ in E. coli $\mathrm{O}_{128}$ and according to the available literature, there was no data on E. coli $\mathrm{O}_{128}$ experimental infection in poultry. Finally, the mortality in the groups inoculated with E. coli $\mathrm{O}_{157}$ was $13.3 \%$ and this rate was higher than that reported by Azza et al. (2018) who recorded a mortality rate of $6.7 \%\left(2\right.$ out of 30) due to E. coli $\mathrm{O}_{157}$ infection in broilers. Among E. coli infected groups, the mortality rate varied with higher mortality recorded in E. coli $\mathrm{O}_{78}$ than the other inoculated two serotypes which may be related to the difference in the virulence genes of $E$. coli serotypes. This interpretation was assessed by Kemmett et al. (2013) who mentioned the contribution of virulence genes present in E. coli serotypes to early broiler deaths. Additionally, the mortalities in the challenged groups that fed on ration containing mycotoxins even with low levels were higher than the $E$. coli challenged groups and feed on diet treated with antimycotoxin and this indicated the effect of mycotoxin on the immune defense mechanism of broiler chickens as mentioned by Park et al. (2015).

Table 2. The mortality rate among all broiler chicken challenged with E. coli $\mathrm{O} 78$, E. coli $\mathrm{O} 128$, and E. coli $\mathrm{O} 157$ during 4 weeks of the experiment

\begin{tabular}{ccc|cc|cccc}
\hline & \multicolumn{2}{c}{ Group 1 } & \multicolumn{2}{c|}{ Group2 } & \multicolumn{2}{c}{ Group 3 } & \multirow{2}{*}{ Control (-ve) } & \multirow{2}{*}{ Control (+ve) } \\
\cline { 2 - 9 } Total & $\mathbf{1 A}$ & $\mathbf{1 B}$ & $\mathbf{2 A}$ & $\mathbf{2 B}$ & $\mathbf{3 A}$ & 3B & 0 & 0 \\
\cline { 2 - 9 } & 3 & 7 & 2 & 3 & 3 & 5 & 0 & 0 \\
\hline$\%$ & $10 \%$ & $23.3 \%$ & $6.66 \%$ & $10 \%$ & $10 \%$ & $16.6 \%$ & 0 & 0
\end{tabular}

A: Fed on ration treated with antimycotoxin, B: Fed on ration containing measured mycotoxin. Group 1, Group 2, and Group 3: Inoculated with E. coli $\mathrm{O} 78$, E. coli $\mathrm{O}_{128}$ and E. coli $\mathrm{O}_{157}$, respectively. 


\section{Feed conversion ratio}

Table 3 and Figure 2 represent the performance parameter (cumulative feed conversion) during the experiment. The E. coli infection in poultry is one of the principal causes of retardation and decreased feed conversion rate and this may be due to lower absorption of nutrients from the inflamed intestinal tract (Abd Elatiff et al., 2019). The performance parameters were the best in the control -ve group followed by control +ve then in the E. coli $\mathrm{O}_{128}$, E. coli $\mathrm{O}_{157}$, and E. coli $\mathrm{O}_{78}$ groups. It was found that there was a significant decrease in body weight gain with bad FCR in groups inoculated with E. coli $\mathrm{O}_{157}$ and these results agreed with Abd Elatiff et al. (2019), also the increase in FCR in the group inoculated with E. coli $\mathrm{O}_{78}$ agreed with Tawab et al. (2015), Elmenawey et al. (2019), and Hassanen et al. (2021). According to Table 3, there was an increase in the FCR in the mycotoxicated challenged groups even with permissible limits of mycotoxin contamination than the challenged groups that feed on a diet treated with antimycotoxin. In the same way, Murugesan et al. (2015) and Abdelnaser et al. (2017) mentioned that mycotoxins have an effect on the broiler performance due to their destructive effects on nutrient digestion and absorption. Furthermore, the malabsorption that occurred due to aflatoxin may have a role in the reduction of body weight as mentioned by Osborne and Hamilton (1981) or may be due to the reduction of the pancreatic enzyme due to the mycotoxin as reported by Richardson and Hamilton (1987). Correspondingly, these results agreed with El Nabarawy et al. (2020) who reported that the naturally contaminated broiler diet by aflatoxin, ochratoxin, and zearalenone at permissible levels resulted in a significant reduction in body weight with a significant increase in FCR.

Table 3. Mean feed conversion ratio of the different broiler chicken groups during the 4 weeks of the experiment

\begin{tabular}{lcccccccc}
\hline \multirow{2}{*}{ Week } & \multicolumn{2}{c}{ Group 1 } & \multicolumn{2}{c}{ Group2 } & \multicolumn{2}{c}{ Group 3 } & \multicolumn{2}{c}{ Control } \\
\cline { 2 - 8 } & $\begin{array}{c}\mathbf{1 ~ A} \\
(\text { mean } \pm \mathrm{SE})\end{array}$ & $\begin{array}{c}\mathbf{1} \mathbf{B} \\
(\text { mean } \pm \mathrm{SE})\end{array}$ & $\begin{array}{c}\mathbf{2 A} \\
(\text { mean } \pm \mathrm{SE})\end{array}$ & $\begin{array}{c}\text { 2B } \\
(\text { mean } \pm \mathrm{SE})\end{array}$ & $\begin{array}{c}\text { 3 A } \\
(\text { mean } \pm \mathrm{SE})\end{array}$ & $\begin{array}{c}\text { 3 B } \\
(\text { mean } \pm \mathrm{SE})\end{array}$ & $\begin{array}{c}\text {-ve } \\
(\text { mean } \pm \mathrm{SE})\end{array}$ & $\begin{array}{c}+ \text { ve } \\
(\mathrm{mean} \pm \mathrm{SE})\end{array}$ \\
\hline $\mathbf{1}$ & $1.5 \pm 0.06^{\mathrm{ab}}$ & $1.6 \pm 0.006^{\mathrm{bc}}$ & $1.4 \pm 0.06^{\mathrm{ab}}$ & $1.7 \pm 0.06^{\mathrm{c}}$ & $1.5 \pm 0.06^{\mathrm{abc}}$ & $1.7 \pm 0.06^{\mathrm{c}}$ & $1.3 \pm 0^{\mathrm{a}}$ & $1.6 \pm 0.06^{\mathrm{bc}}$ \\
\hline $\mathbf{2}$ & $1.7 \pm 0^{\mathrm{a}}$ & $2.5 \pm 0.09^{\mathrm{c}}$ & $1.7 \pm 0.06^{\mathrm{a}}$ & $2 \pm 0.06^{\mathrm{ab}}$ & $1.9 \pm 0.09^{\mathrm{ab}}$ & $2.2 \pm 0.06^{\mathrm{b}}$ & $1.7 \pm 0^{\mathrm{a}}$ & $2.2 \pm 0.09^{\mathrm{b}}$ \\
\hline $\mathbf{3}$ & $2.1 \pm 0.06^{\mathrm{d}}$ & $2.5 \pm 0.06^{\mathrm{e}}$ & $1.6 \pm 0.03^{\mathrm{ab}}$ & $1.9 \pm 0.03^{\mathrm{cd}}$ & $1.6 \pm 0.06^{\mathrm{bc}}$ & $2 \pm 0.03^{\mathrm{d}}$ & $1.4 \pm 0.03^{\mathrm{a}}$ & $1.9 \pm 0.06^{\mathrm{cd}}$ \\
\hline $\mathbf{4}$ & $2.8 \pm 0.06^{\mathrm{bcd}}$ & $3.1 \pm 0.09^{\mathrm{d}}$ & $2.6 \pm 0.09^{\mathrm{bc}}$ & $2.9 \pm 0.06^{\mathrm{cd}}$ & $2.7 \pm 0.06^{\mathrm{bc}}$ & $3 \pm 0.03^{\mathrm{d}}$ & $2.1 \pm 0.03^{\mathrm{ab}}$ & $2.5 \pm 0.03^{\mathrm{bc}}$ \\
\hline
\end{tabular}

A: Fed on antimycotoxin treated ration, B: Fed on ration containing Afla and Ochratoxins, Mean \pm SE: Mean \pm standard error, ${ }^{\text {a,b,c,d }}$ Means different letters in the same row are significantly different $(\mathrm{p} \leq 0.05)$. Group 1 , Group 2 , and Group 3 : Inoculated with E. coli O 78, E. coli $\mathrm{O}_{128}$, and $E$. coli $\mathrm{O}_{157}$, respectively.

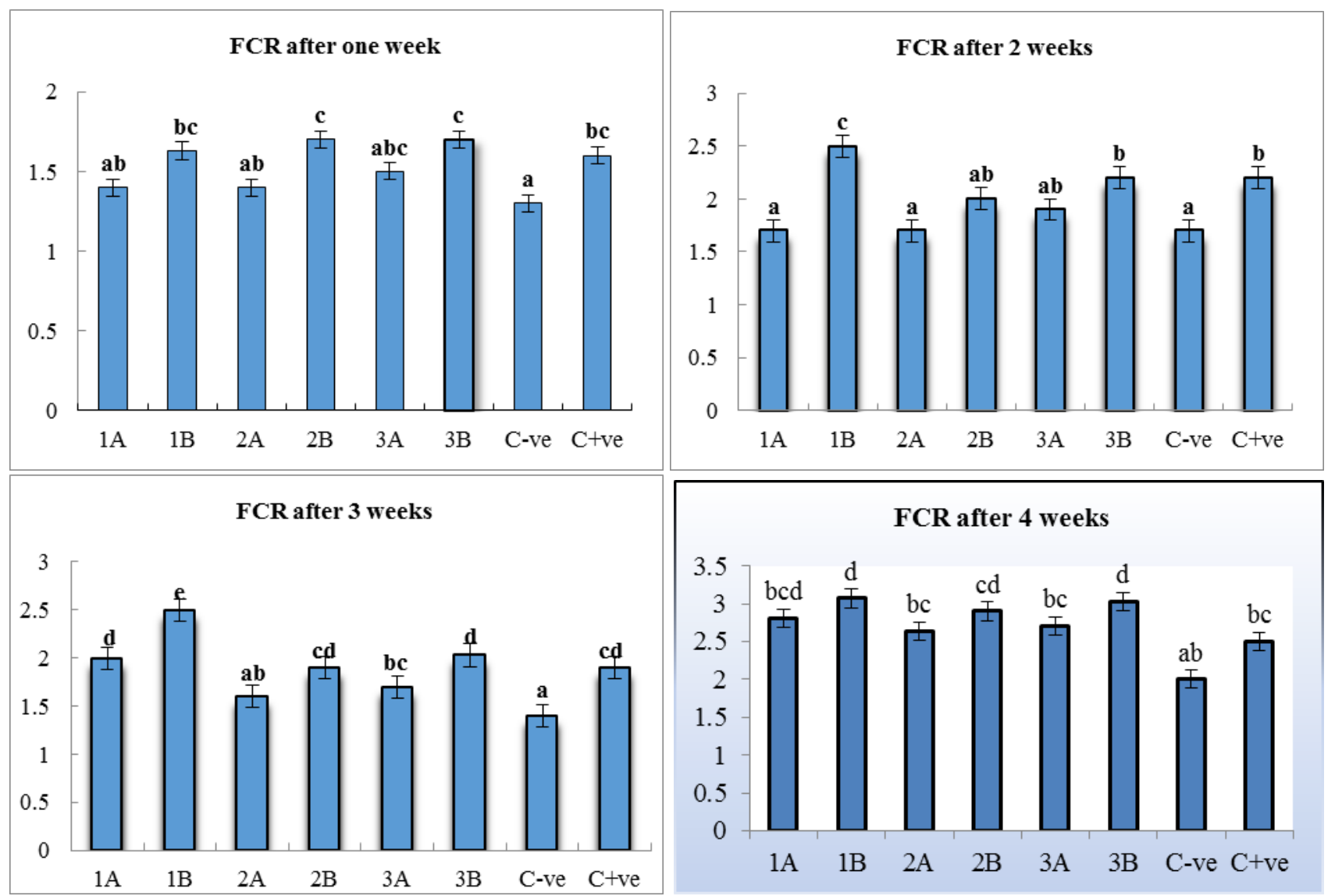

Figure 2. FCR of broiler chickens challenged with E. coli O78, E. coli O128, and E. coli O157 during four weeks of the experimentation. A: Fed on antimycotoxin treated ration, B: Fed on ration containing Afla and Ochratoxins, ${ }^{\text {a,b,c,d }}$ means different letters in the same week are significantly different $(\mathrm{p} \leq 0.05)$. Group 1 , Group 2, and Group 3: Inoculated with E. coli O 78, E. coli O128, and E. coli O157, respectively 


\section{Re-isolation of Escherichia coli in the groups under experiment (organ colonization)}

In the present study, the challenged groups with $E$. coli $\mathrm{O}_{78}$ showed the re-isolation rate of $77.7 \%$ from organs (66.6\% from liver, $100 \%$ from spleen, and $66.6 \%$ from heart ) while these percentages increased in mycotoxicated challenged groups to reach an average of $88.8 \%$ (100\% from liver, $100 \%$ from spleen, and $66.6 \%$ from heart) at the firstweek post-inoculation. These percentages declined weekly to reach $44 \%$ and $55.5 \%$ in challenged and mycotoxicated challenged groups at the second-week post-inoculation, while at the third-week post-inoculation, the organ colonization was reduced to be $11 \%$ in both subgroups. Similarly, these percentages of re-isolation in groups inoculated with E. coli $\mathrm{O}_{128}$ were $88.8 \%$ in the first week post-inoculation in both subgroups $\mathrm{A}$ and $\mathrm{B}$ and decreased to be $55.5 \%$ in the second week, and at the third week post-inoculation no isolates were detected in the challenged group, whilst at the mycotoxicated challenged groups, the re-isolation rate was $22.2 \%$. On the other hand, the re-isolation rate from organs in subgroup A inoculated with E. coli $\mathrm{O}_{157}$ was $77.7 \%$, while this percentage increased to $100 \%$ in subgroup B at the firstweek post-inoculation. These percentages reduced at the second week to be $44.4 \%$ and $77.7 \%$ in subgroup A and subgroup B, respectively, and at the third week post-inoculation the re-isolation rates were $11 \%$ and $22 \%$ in the subgroups A and B, respectively (Table 4)

From these results, the mycotoxicated groups even the acceptable range of mycotoxins were showing $E$. coli reisolation rate higher than the antimycotoxin treated groups. These results were in line with the explanation of Park et al. (2015) indicating that some mycotoxins interfere with host defenses against $E$. coli, resulting in bacterial clearance failure and promoting mucosal colonization, invasion, and inflammatory responses. Similarly, Devriendt et al. (2009) found that dietary fumonisin B1 $(0.5 \mathrm{mg} / \mathrm{kg}$, in vivo $)$ significantly increases E. coli colonization in the small and large intestines, as well as subsequent bacterial translocation to extraintestinal organs such as the mesenteric lymph nodes, lung, liver, and spleen, resulting in longer $E$. coli shedding after infection.

\section{Histopathology}

At the first-week post-infection, the control -ve group showed no histopathological alterations with the normal histological structure of liver hepatocytes (Figure 3G)., normal white and red pulp of the spleen, as well as the normal length of intestinal villi. On the other hand, in the control +ve group, the liver showed periportal fatty degeneration with lymphoid depletion in the spleen (Figure $3 \mathrm{H}$ ) with a decrease of intestinal villi length. In the E. coli $\mathrm{O}_{78}$ challenged group, the liver of broiler chicks revealed congestion of portal blood vessels associated with marked vasculitis, severe degree of lymphoid depletion as well as reticular fibers within the white pulp of the spleen. Intestine showed necrotic enteritis associated with sloughing of the mucosal epithelium (Figure 3A). Moreover, the liver of the mycotoxicated $E$. coli $\mathrm{O}_{78}$ challenged group showed severe vasculitis associated with hemorrhage and a severe degree of fatty changes (Figure 3B), meanwhile the spleen showed a severe degree of lymphoid necrosis. Intestine showed a severe degree of necrotic enteritis associated with sloughing of the mucosal epithelium (Figure 3A). These observations were like those detected by Sahar and El-shazly (2002), Riaz et al. (2016), and Awaad et al. (2021) who found that E. coli $\mathrm{O}_{78}$ caused perihepatitis, hepatocyte vascular degeneration, and infiltration of mononuclear leucocytes, inflammatory cells, and portal vein dilatation. Liver of chickens challenged with E. coli $\mathrm{O}_{157}$ indicated hepatic vacuolar degeneration with a marked degree of lymphoid depletion in the spleen (Figure 3E), while intestine showed mild to moderate degree of necrotic enteritis associated with sloughing of the mucosal epithelium. In mycotoxicated chicken group challenged with E. coli $\left(\mathrm{O}_{157}\right)$, the liver showed hepatitis associated with vasculitis and severe degree of fatty changes. Moreover, spleen showed a severe degree of lymphoid necrosis (Figure 3F) and the intestine showed a severe degree of necrotic enteritis. These observations were similar to those detected by Dutta et al. (2013), and Azza et al. (2018).

In the chickens challenged with E. coli $\left(\mathrm{O}_{128}\right)$, the liver showed marked fatty degenerative changes within hepatocytes (Figure 3C), lymphoid depletion within the white pulp in the spleen, and a moderate degree of catarrhal enteritis in the intestine. On the other hand, the liver of mycotoxicated chickens challenged with $E$. coli $\left(\mathrm{O}_{128}\right)$ indicated a focal area of coagulative necrosis associated with mononuclear cells infiltration (Figure 3D), marked degree of lymphoid depletion in the spleen, and a moderate degree of necrotic enteritis in the intestine. These lesions were similar to those detected by Nataro and Kaper (1998). The histopathological changes decreased gradually from the second week (Figure 4), then a third week (Figure 5) till the fourth week of age (Figure 6) at the E. coli challenged groups with the absence of mycotoxins effect, in contrary with the mycotoxicated $E$. coli challenged groups which indicates that the presence of mycotoxin aggravate the condition and prolong the time needed for tissue repair. These results were in line with these recorded by Kubena et al. (1985), and Elaroussi et al. (2006). Likewise, Kumar et al. (2004) reported severe histopathological changes in poultry infected with $E$. coli and fed with mycotoxin, compared to those infected with $E$. coli only. Moreover, the histopathological changes increased weekly in the control +ve group, which was in line with a study by Bakeer et al. (2013) indicating that the pathological changes increased in correlation with prolonged administration of mycotoxins (Table 5). 


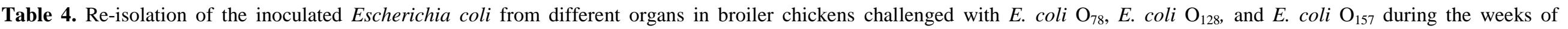
experimentation

\begin{tabular}{|c|c|c|c|c|c|c|c|c|c|c|c|c|c|c|c|c|}
\hline \multirow{2}{*}{$\begin{array}{l}\text { WPI } \\
\text { Group }\end{array}$} & \multicolumn{3}{|c|}{ W1 } & \multicolumn{3}{|c|}{ W2 } & \multicolumn{3}{|c|}{ W3 } & \multicolumn{3}{|c|}{ W4 } & \multicolumn{3}{|c|}{ Total organs isolation } & \multirow{2}{*}{ Total } \\
\hline & Liver & Spleen & Heart & Liver & spleen & Heart & liver & spleen & Heart & liver & Spleen & Heart & liver & spleen & Heart & \\
\hline $\mathbf{1 A}$ & $66 \%$ & $100 \%$ & $66 \%$ & $33 \%$ & $33 \%$ & $66 \%$ & 0 & $33.3 \%$ & 0 & 0 & $33 \%$ & 0 & $25 \%$ & $50 \%$ & $33 \%$ & $36 \%$ \\
\hline 1B & $100 \%$ & $100 \%$ & $66 \%$ & $33 \%$ & $66 \%$ & $33 \%$ & $33 \%$ & 0 & 0 & $33 \%$ & 0 & 0 & 50 & 41.5 & 25 & $39 \%$ \\
\hline $2 \mathrm{~A}$ & $66 \%$ & $100 \%$ & $100 \%$ & 0 & $100 \%$ & $66 \%$ & 0 & 0 & 0 & 0 & 0 & 0 & 16.5 & 50 & 41.5 & $27 \%$ \\
\hline 2B & $100 \%$ & $66 \%$ & $100 \%$ & $33 \%$ & $66 \%$ & $66 \%$ & 0 & $33 \%$ & $33 \%$ & 0 & 0 & $33 \%$ & 33.5 & 41.5 & 50 & $31 \%$ \\
\hline $\mathbf{3 A}$ & $100 \%$ & $66 \%$ & $66 \%$ & $66 \%$ & $33 \%$ & $33 \%$ & 0 & $33 \%$ & 0 & 0 & $33 \%$ & 0 & 41.5 & 41.5 & 25 & $27 \%$ \\
\hline 3B & $100 \%$ & $100 \%$ & $100 \%$ & $66 \%$ & $100 \%$ & $66 \%$ & $33 \%$ & $33 \%$ & 0 & 0 & 0 & 0 & 50 & 58.5 & 41.5 & $50 \%$ \\
\hline C -ve & 0 & 0 & 0 & 0 & 0 & 0 & 0 & 0 & 0 & 0 & 0 & 0 & 0 & 0 & 0 & 0 \\
\hline C+ve & 0 & 0 & 0 & 0 & 0 & 0 & 0 & 0 & 0 & 0 & 0 & 0 & 0 & 0 & 0 & 0 \\
\hline
\end{tabular}

A: Fed on ration treated with antimycotoxin, B: Fed on a ration containing measured mycotoxins, W: Week, C+ve: Control positive, C-ve: Control negative, WPI: Week post-infection

Table 5. Cumulative histopathological changes for broiler chicken challenged with E. coli $\mathrm{O}_{78}$, E. coli $\mathrm{O}_{128}$, and E. coli $\mathrm{O}_{157}$ during the 4 weeks of the experiment

\begin{tabular}{|c|c|c|c|c|c|c|c|c|}
\hline & \multicolumn{2}{|c|}{ Group 1 (Escherichia coli $\left.\mathrm{O}_{78}\right)$} & \multicolumn{2}{|c|}{ Group 2 (Escherichia coli $\left.\mathrm{O}_{128}\right)$} & \multicolumn{2}{|c|}{ Group 3 (Escherichia coli $\mathrm{O}_{157}$ ) } & \multirow{2}{*}{ Negative ontrol } & \multirow{2}{*}{ Positive control } \\
\hline & $1 \mathbf{A}$ & $1 \mathbf{B}$ & $2 \mathrm{~A}$ & 2 B & $3 \mathrm{~A}$ & $3 \mathbf{B}$ & & \\
\hline Week 1 & 11 & 15 & 11 & 13 & 12 & 15 & 0 & 3 \\
\hline Week 2 & 9 & 14 & 8 & 10 & 9 & 12 & 0 & 4 \\
\hline Week 3 & 6 & 9 & 6 & 7 & 7 & 9 & 0 & 7 \\
\hline Week 4 & 5 & 8 & 5 & 6 & 6 & 8 & 0 & 9 \\
\hline
\end{tabular}

The lesion scores were determined as follow, 1: Hepatic lesions 9 scores (3 points degeneration, 3 necrosis, and 3 inflammation) 2: Lymphoid depletion in spleen 3 scores 3: Enteritis 3 scores 


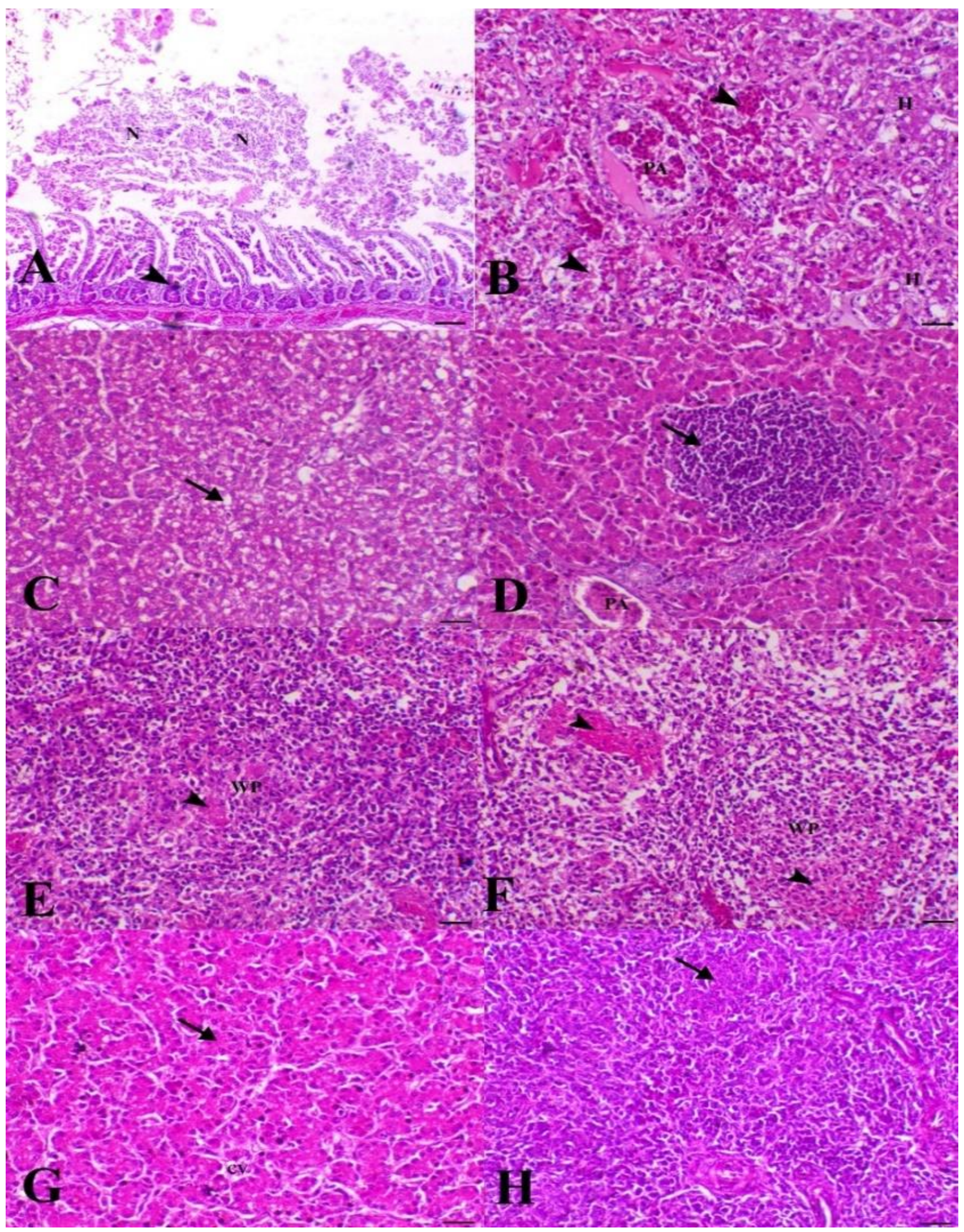

Figure 3. Histopathological lesions of broiler chickens at first week post-infection with different E. coli serotypes. A: Intestine of broiler chickens challenged with E. coli $\left(\mathrm{O}_{78}\right)$ showing necrotic enteritis associated with sloughing of the mucosal epithelium, B: Liver of mycotoxicated chicken challenged with $E$. coli $\left(\mathrm{O}_{78}\right)$ showing severe vasculitis associated with haemorrhage (arrowhead) associated with severe degree of fatty changes, $\mathbf{C}$ : Liver of chicken challenged with E. coli $\left(\mathrm{O}_{128}\right)$ showing marked fatty degenerative changes within hepatocytes, D: Liver of mycotoxicated chicken challenged with E. coli $\left(\mathrm{O}_{128}\right)$ showing focal area of coagulative necrosis associated with mononuclear cells infiltration, E: Spleen of chicken challenged with E. coli $\left(\mathrm{O}_{157}\right)$ showing marked degree of lymphoid depletion associated with deposition of fibrin (arrowhead) within the white pulp, F: Spleen of mycotoxicated chicken challenged with E. coli $\left(\mathrm{O}_{157}\right)$ showing severe degree of lymphoid necrosis associated with marked deposition of fibrin exudate within white pulp, G: Liver of control negative chicken showing normal hepatocytes around the central vein and H: Spleen of control positive chickens showing lymphoid depletion associated with marked histiocytic cells proliferation. 


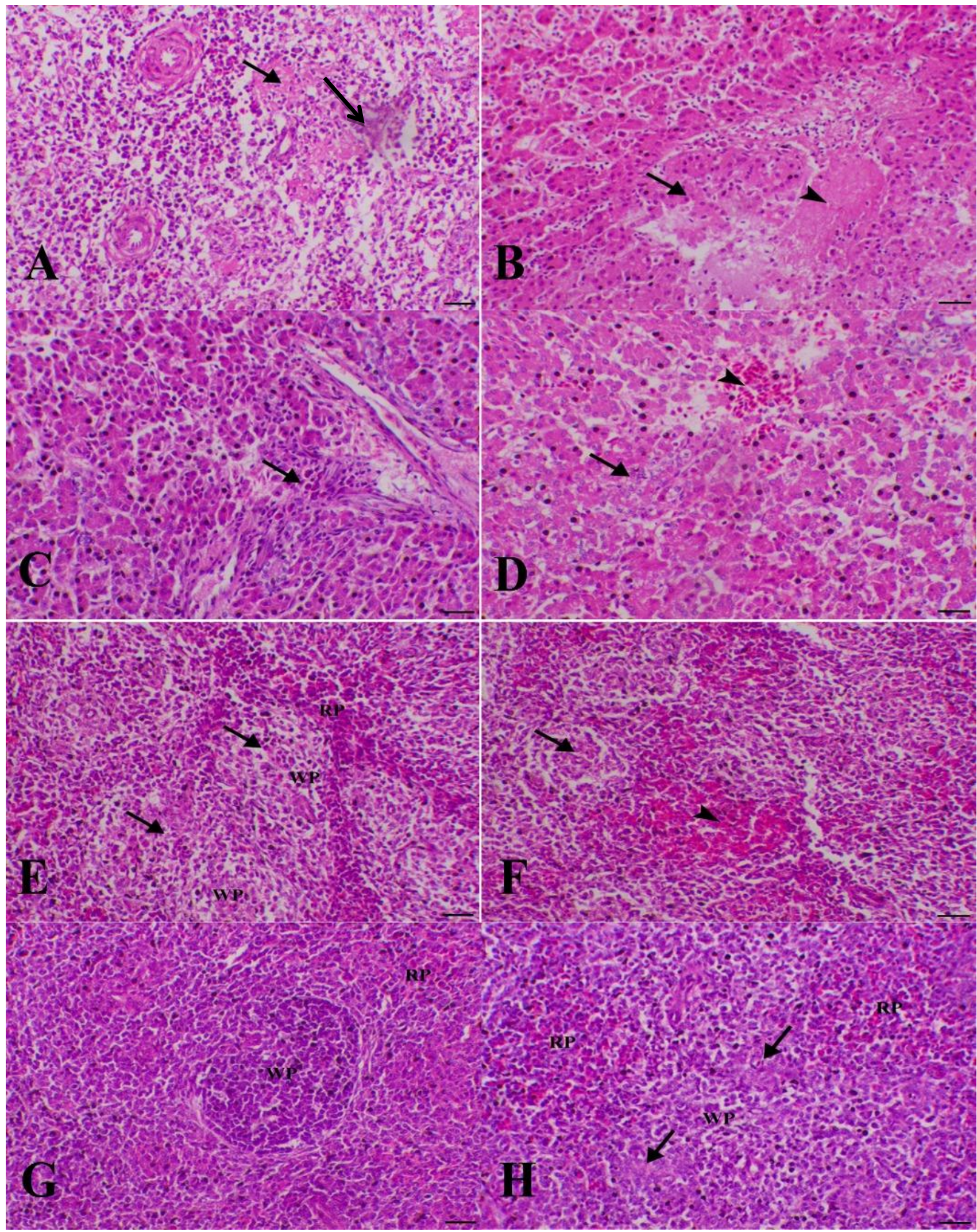

Figure 4. Histopathological lesions of broiler chickens at second week post infection with different E. coli serotypes. A: Spleen of chicken challenged with E. coli $\left(\mathrm{O}_{78}\right)$ showing severe degree of lymphoid necrosis associated with fibrin deposition, B: Liver of mycotoxicated chicken challenged with E. coli $\left(\mathrm{O}_{78}\right)$ showing severe coagulative necrosis (arrow) associated with marked deposition of fibrinoid-like materials, C: Liver of chicken challenged with E. coli $\left(\mathrm{O}_{128}\right)$ showing periportal hepatic necrosis associated with heterophilic cells infiltration, D: Liver of mycotoxicatedchicken challenged with E. coli $\left(\mathrm{O}_{128}\right)$ showing hepatic degeneration (arrow) and focal haemorrhage (arrowhead), E: Spleen of chicken challenged with E. coli $\left(\mathrm{O}_{157}\right)$ showing marked degree of lymphoid depletion which replaced with marked histocytic cells infiltration (arrows) within the white pulp, F: Spleen of mycotoxicated chicken challenged with E. coli $\left(\mathrm{O}_{157}\right)$ showing severe congestion of the red pulp (arrowhead) accompanied with lymphoid necrosis, G: Spleen of control chicken showing normal white pulp and red pulp and H: Spleen of control positive chickenshowing congestion of the red pulp and lymphoid depletion of the white pulp. 


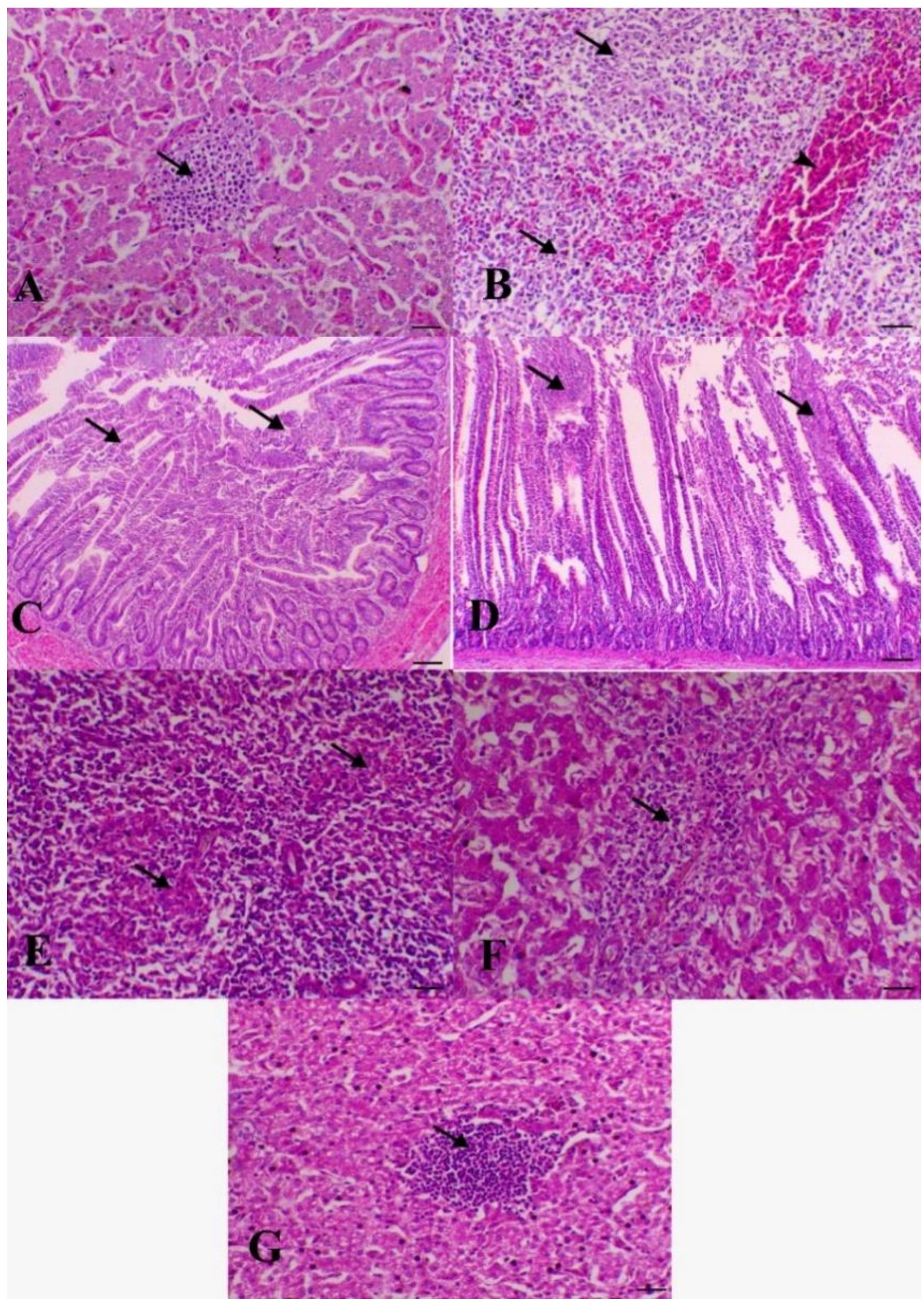

Figure 5. Histopathological lesions of the broiler chickens at third week post-infection with different $E$. coli serotypes. A: Liver of broiler chickens challenged with E. coli $\left(\mathrm{O}_{78}\right)$ showing marked sinusoidal congestion and focal coagulative necrosis associated with mononuclear cells infiltration, B: Spleen of mycotoxicated chicken challenged with E. coli $\left(\mathrm{O}_{78}\right)$ showing marked congestion and haemorrhage of the red pulp (arrowhead) and marked degree of lymphoid necrosis replaced with histocytes, C: Intestine of chicken challenged with E. coli $\left(\mathrm{O}_{128}\right)$ showing necrosis and sloughing of the intestinal villi, D: Intestine of mycotoxicated chicken challenged with E. coli $\left(\mathrm{O}_{128}\right)$ showing marked degree of necrotic enteritis, E: Spleen of chicken challenged with $E$. coli $\left(\mathrm{O}_{157}\right)$ showing marked degree of lymphoid depletion with marked histiocytic cells proliferation, F: Liver of mycotoxicated broiler chickens challenged with E. coli $\left(\mathrm{O}_{157}\right)$ showing marked vasculitis, periportal hepatic necrosis and marked mononuclear cells infiltration and G: Liver of control positive chicken showing focal necrosis associated with mononuclear inflammatory cells infiltration mostly lymphocytes and macrophages. 

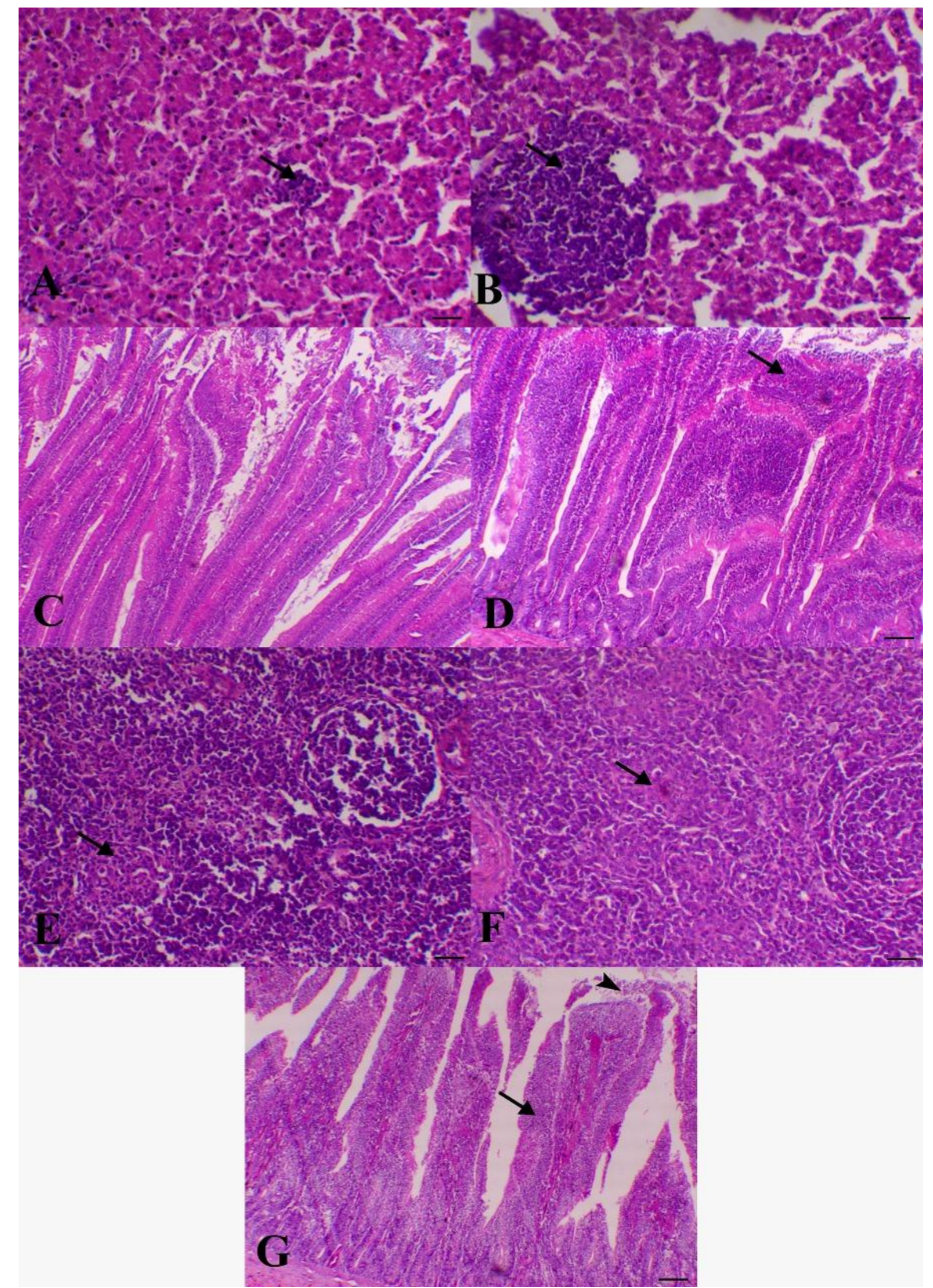

Figure 6. Histopathological lesions of broiler chickens at fourth week post-infection with different $E$. coli serotypes. A: Liver of chicken challenged with E. coli $\left(\mathrm{O}_{78}\right)$ showing small necrotic foci associated with mononuclear cells infiltration B: Liver of mycotoxicated broiler chickens challenged with E. coli $\left(\mathrm{O}_{78}\right)$ showing large necrotic foci associated with mononuclear cells infiltration C: Intestine of chicken challenged with E. coli $\left(\mathrm{O}_{128}\right)$ showing necrosis and sloughing of the intestinal most upper portions of the villi D: Intestine of mycotoxicated broiler chickens challenged with E. coli $\left(\mathrm{O}_{128}\right)$ showing shortening and blunting of the villi E: Spleen of chicken challenged with E. coli $\left(\mathrm{O}_{157}\right)$ showing moderate degree of lymphoid depletion with marked histiocytic cells proliferation F: Spleen of mycotoxicated chicken challenged with E. coli $\left(\mathrm{O}_{157}\right)$ showing marked lymphoid necrosis associated with perivascular histocytes proliferation G: Intestine of control positive chicken showing desqumative changes within the intestinal epithelium (arrowheads) associated with marked goblet cells hyperplasia. 


\section{CONCLUSION}

In conclusion, the previous results indicated that mycotoxins even at low levels worsen the clinical signs, mortalities, body weight, and feed conversion rate of the grown chickens when get infected with pathogenic strains as avian pathogenic E. coli. Thus, every endeavor should be adopted to reduce feed contamination with these mycotoxins.

\section{DECLARATION}

\section{Ethical considerations}

Ethical issues including plagiarism, consent to publish, misconduct, data fabrication and/or falsification, double publication and/or submission, and redundancy have been checked by the authors.

\section{Competing interests}

The authors declare that they have no conflict of interest.

\section{Authors' contributions}

Anwaar Mettwally El-nabarawy and designed and supervised the experiment. Mohamed Abdel-Salam Shakal supervised the experiment. Mohamed Bateekh, Abdel-Haleem Mohamed Hegazy, and Eman Anter Morsy performed the experiment and wrote the manuscript. Mohamed Bateekh performed the statistical analysis. All authors read and approve the manuscript.

\section{Acknowledgments}

The authors are thankful to the Faculty of Veterinary Medicine, Cairo University, and Animal health research institute-Kafr El-sheikh provisional lab, agriculture research center in Egypt for providing lab facilities and facilitating the experiment conduction. The authors also would like to thank Dr. Walied Abdo Sobhy, department of Veterinary Pathology, Kafr El-sheikh University, Egypt, for performing the histopathological examination.

\section{REFERENCES}

Abd Elatiff A, El-Sawah A, Amer MM, Dahshan AM, Salam H, and Shany SAS (2019). Pathogenicity of Escherichia coli $\mathrm{O}_{125}$ in commercial broiler chickens. Journal of Veterinary Medical Research, 26(1): 1-8. DOI: https://www.doi.org/10.21608/JVMR.2019.43328

Abd El-Ghany WA, and Madian K (2011). Control of experimental colisepticaemia in broiler chickens using sarafloxacin. Life Science. Journal, 8(3): 318-328. Available at: http://www.lifesciencesite.com.

Abdelnaser AH, El Nabarawy AM, Zyan KA, and Abd El Magid AD (2017). Evaluation of the economic efficacy of some antimycotoxicosis compounds on production and humoral immunity in broiler chickens. Journal of Advanced Veterinary Research, 7(4): 100-107. Available at: http://advetresearch.com/index.php/avr/index

Awaad MHH, El Moustafa KM, Zoulfakar SA, Elhalawany MS, Mohammed FF, El-Refay RM, and Morsy EA (2021). The role of silver nanoparticles in the reluctance of colisepticemia in broiler chickens. Journal of Applied Poultry Research, $30(2): 100155$. DOI: https://www.doi.org/10.1016/j.japr.2021.100155

Azza A, Dahshan AHM, El-Nahass ES, and Abd El-Mawgoud AI (2018). Pathogenicity of Escherichia coli $\mathrm{O}_{157}$ in commercial broiler chickens. Beni-Suef University Journal of Basic and Applied Sciences, 7(4): 620-625. DOI: https://www.doi.org/10.1016/j.bjbas.2018.07.005

Bakeer AM, Farid AS, and Gad ElKarim MF (2013). The Hepatotoxic and Nephrotoxic Effects of Mycotoxin in Broiler Chickens. Benha Veterinary Medical Journal, 25: 29-45. Available at: https://www.bvmj.bu.edu.eg/issues/25-1/4.pdf

Bancroft JD, and Stevens A (1990). Theory and practice of histological techniques churchul livingstone Edinbrugh, eight edition pp.766 DOI: https://www.doi.org/10.1002/path.1711640316

Boermans HJ, and Leung MC (2007). Mycotoxins and the pet food industry: Toxicological evidence and risk assessment. International Journal of Food Microbiology, 119: 95-102. DOI: https://www.doi.org/10.1016/j.ijfoodmicro.2007.07.063

Devriendt B, Verdonck F, Wach Y, Bimczok D, Oswald IP, Goddeeris BM, and Cox E (2009). The food contaminant fumonisin B reduces the maturation of porcine CD11R1 intestinal antigen presenting cells and antigen-specific immune responses, leading to a prolonged intestinal ETEC infection. Veterinary Research, 40(4): 1-14. DOI: https://www.doi.org/10.1051/vetres/2009023

Dutta P, Borah MK, Sarmah R, and Gangil R (2013). Isolation, histopathology and antibiogram of Escherichia coli from pigeons (Columba livia). Veterinary World, 6(2): 91-94. DOI: https://www.doi.org/10.5455/vetworld.2013.91-94

Elmenawey MA, Mohammed FA, Morsy EA, Abdel-Alim GA, and Awaad MHH (2019). The impact of essential oils blend on experimental colisepticemia in broiler chickens. International Journal of Veterinary Science, 8(4): 294-299. Available at: https://scholar.cu.edu.eg/sites/default/files/gabdullalim/files/the_impact_of_blended_oil.pdf

El Nabarawy AM, Ismael E, Shaaban KA, El Basuni SS, Batikh MM, and Shakal M (2020). Mycotoxins contamination levels in broiler Feeds and aflatoxin residues in broiler Tissues. Journal of World Poultry Research, 10: 133-144. DOI: https://www.doi.org/10.36380/jwpr.2020.18

Filazi A, Yurdakok-Dikmen B, Kuzukiran O, and Sireli UT (2017). Mycotoxins in poultry. Poultry Science, Dr. Milad Manafi (Ed.), InTech, 73-92. DOI: https://www.doi.org/10.5772/66302 
Hassanen EI, Morsy EA, Hussien AM, Farroh KY, and Ali ME (2021). Comparative assessment of the bactericidal effect of nanoparticles of copper oxide, silver, and chitosan-silver against Escherichia coli infection in broilers. Bioscience Reports, pp 41(4): BSR20204091. DOI: https://www.doi.org/10.1042/BSR20204091

Hegazy AM (1991). Studies on salmonella infections in ducks. M.V.SC. Thesis. Faculty of Vetrinary Medicine, alexandria. University. Available at: http://srv4.eulc.edu.eg/eulc_ v5/Libraries/Thesis/BrowseThesisPages.aspx?fn=PublicDrawThesis\&BibID=9991624

Ibrahiem M, Samer M, and Adel A (2016). Dual effect of Aspergillus Fumigatus and E. coli $\mathrm{O}_{125}$ in broilers. Benha Veterinary Medical Journal, 30(1): 283-294. DOI: https://www.doi.org/10.21608/bvmj.2016.31377

Kemmett K, Williams NJ, Chaloner G, Humphrey S, Wigley P and Humphrey T (2013). The contribution of systemicEscherichia coliinfection to the early mortalities of commercial broiler chickens. Avian Pathology, 43(1), 37-42. DOI: https://www.doi.org/10.1080/03079457.2013.866213

Kubena LF, Harvey RB, Fletcher OJ, Phillips TD, Mollenhauer HH, Witzel DA, and Heidelbaugh ND (1985). Toxicity of ochratoxin A and vanadium to growing chicks. Poultry science 64(4): 620-628. DOI: https://www.doi.org/10.3382/ps.0640620.

Kumar A, Jindal N, Shukla CL, Asrani RK, Ledoux DR, and Rottinghaus GE (2004). Pathological changes in broiler chickens fed ochratoxin A and inoculated with Escherichia coli. Avian Pathology 33(4): 413-417. DOI: https://www.doi.org/10.1080/03079450410001724021

Elaroussi MA, Mohamed FR, El Barkouky EM, Atta AM, Abdou AM, and Hatab MH (2006). Experimental ochratoxicosis in broiler chickens. Avian Pathology, 35(4): 263-269. DOI: https://www.doi.org/10.1080/03079450600817115

Moon EY, Rhee DK, and Pyo S (1999). In vitro suppressive effect of aflatoxin B1 on murine peritoneal macrophage functions. Toxicology, 133:171-179. DOI: https://www.doi.org/10.1016/S0300-483X(99)00023-2

Murugesan GR, Ledoux DR, Naehrer K, Berthiller F, Applegate TJ, Grenier B, and Schatzmayr G (2015). Prevalence and effects of mycotoxins on poultry health and performance, and recent development in mycotoxin counteracting strategies. Poultry science, 94(6): 1298-1315. DOI: https://www.doi.org/10.3382/ps/pev075

Nataro JP, and Kaper JB (1998). Diarrheagenic Escherichia coli. Clinical Microbiology Reviews, 11(1): 142-201. DOI: https://www.doi.org/10.1128/CMR.11.1.142

Njobeh PB, Dutton MF, Åberg AT, and Haggblom P (2012). Estimation of multi-mycotoxin contamination in South African compound feeds. Toxins, 4(10): 836-848. DOI: https://www.doi.org/10.3390/toxins4100836

North, M. O. (1984): Broiler, Roaster, and Capon management Ch.20, P.387. In commercial chicken production Manual, third Edition By The AVI publishing Company Inc, West Port Connecticut. Available at https://www.cabdirect.org/cabdirect/abstract/19840180814

Osborne DJ, Hamilton PB (1981). Decreased pancreatic digestive enzymes during aflatoxicosis. Poultry Science, 60(8): 18181821. DOI: https://www.doi.org/10.3382/ps.0601818

Park SH, Kim D, Kim J, and Moon Y (2015). Effects of mycotoxins on mucosal microbial infection and related pathogenesis. Toxins, 7(11): 4484-4502. DOI: https://www.doi.org/10.3390/toxins7114484

Riaz AM, Aslam A, Rehman M, and Yaqub T (2016). Pathological investigation and molecular detection of avian pathogenic E. coli serogroups in broiler birds. Journal of Vetrinary Science and Technology, 7: 373. DOI: https://www.doi.org/10.4172/21577579.1000373

Richardson KE, and Hamilton PB (1987). Enhanced production of pancreatic digestive enzymes during aflatoxicosis in egg-type chickens. Poultry Science, 66(4): 640-644. DOI: https://www.doi.org/10.3382/ps.0660640

Rodrigues I, and Naehrer K (2012). Prevalence of mycotoxins in feedstuffs and feed surveyed worldwide in 2009 and 2010. Phytopathologia Mediterranea, 175-192. Available at: https://www.jstor.org/stable/43872365

Sahar A, and El-shazly M (2002). Effect of probiotic and prebiotic combination (Biomin IMBO and Biomin C-EX) on E. coli infection in broiler chickens. Journal of Egyptian Vetrinary Medical Association, 62(6): 113-119. http://www.lifesciencesite.com

(SAS) Statistical Analysis System (2004). SAS User's Guide, Statistics, Version 6.12 edition. SAS Institute Inc., Cary, NC.USA.170PP.

Shamsudeen P, Shrivastava HP, Singh R, and Chandra D (2013). Effect of chelated and inorganic trace minerals on aflatoxin synthesis in maize. Journal of Poultry Science and Technology, 1(1): 13-16. Available at: http://jakraya.com/journal/pdf/jpstArticle_3.pdf

Shen-Orr SS, Milo R, Mangan S, and Alon U (2002). Network motifs in the transcriptional regulation network of Escherichia coli. Nature Genetics, 31(1): 64-68. DOI: https://www.doi.org/10.1038/ng881

Snedecor GW, and Cochran WG (1980). Statistical Methods, 7th edition. The Iowa State University Press. Ames, IA. DOI: https://www.doi.org/10.1201/9780203738573

Sojka WJ, Carnaghan RBA (1961). Escherichia coli infection in poultry. Research in Veterinary Science, 2: 340-352. DOI: https://www.doi.org/10.1016/S0034-5288(18)34938-5

Stordeur P, and Mainil J (2002). Colibacillosis in poultry. Annales de Medecine Veterinaire, 146: 11-18. DOI: https://www.doi.org/10.3126/janr.v2i1.26094

Streit E, Schatzmayr G, Tassis P, Tzika E, Marin D, Taranu I, and Oswald IP (2012). Current situation of mycotoxin contamination and co-occurrence in animal feed-Focus on Europe. Toxins, 4(10): 788-809. DOI: https://www.doi.org/10.3390/toxins4100788

Tawab AA, KOMy AA, Khalid EE, Ekhnaw I, and Talaie AT (2015). Effect of fosfomycin on E. coli $\mathrm{O}_{78}$ isolated from broiler chickens in-vitro and in vivo. Benha Vetrinary Medical Journal, 28: 294-300. Available at: http://www.bvmj.bu.edu.eg

Timmerman HM, Veldman A, van den Elsen E, Rombouts FM, and Beynen AC (2006). Mortality and growth performance of broilers given drinking water supplemented with chicken-specific probiotics. Poultry Science, 85: 1383-1388. https://doi.org/10.1093/ps/85.8.1383 